\title{
Measurement of Gamma-Rays Induced Luminescence Generated in a Sapphire Based Fiber-Optic Radiation Sensor
}

\author{
Young Beom Song1, Kyoung Won Jang', Hye Jin Kim¹, Dong Eun Lee², Mingeon Kim¹, \\ Sang Hun Shin ${ }^{2}$, Wook Jae Yoo², Bongsoo Lee ${ }^{{ }^{*}}$ \\ ${ }^{1}$ School of Energy Systems Engineering, Chung-Ang University, Seoul, Korea \\ ${ }^{2}$ School of Biomedical Engineering, BK21 plus Research Institute of Biomedical Engineering, \\ Konkuk University, Chungju-si, Korea \\ Email: "bslee@cau.ac.kr
}

Received 14 July 2016; accepted 8 August 2016; published 15 August 2016

\begin{abstract}
In this study, we fabricated a sapphire based fiber-optic radiation sensor. To evaluate the fiberoptic radiation sensor, we measured the spectrum and intensity of the luminescence generated from the fiber-optic radiation sensor according to the thickness of the PMMA block by irradiation of gamma rays emitted from a Co-60 source. And the result was compared with the value calculated from the formula of Lambert-Beer.
\end{abstract}

\section{Keywords}

Fiber-Optic Radiation Sensor, Optical Glass, Sapphire, Luminescence, Gamma Ray Source, Spent Fuel

\section{Introduction}

In general, the fiber-optic radiation sensors (FORSs) have many advantages such as good flexibility and no interferences from pressure, humidity, and electromagnetic field [1]-[3]. In addition, the FORSs can be used in narrow spaces with high spatial resolution due to their small sizes. Owing to these advantages, the FORSs have been developed to detect some ionizing radiations in hazardous radiation fields [4] [5]. Meanwhile, the radiation induced luminescence (RIL) such as Cerenkov radiation and fluorescence can be frequently observed in a spent fuel storage pit. Since the luminescence is generated by interactions between the ionizing radiations and transparent media, this type of light signal can be a significant signal in some cases [6] [7].

The purpose of this study is to detect ionizing radiations in the hazardous conditions by measuring the RIL. The RIL can be generated in various fiber-optic materials. In previous research, a FORS using the RIL was fabricated to verify spent fuel in a nuclear power plant; here, the silica optical fiber was employed as a sensor probe [8]. To enhance signal to noise ratio (SNR) of the FORS, in this study, we fabricated a sapphire based

\footnotetext{
${ }^{*}$ Corresponding author.
}

How to cite this paper: Song, Y.B., Jang, K.W., Kim, H.J., Lee, D.E., Kim, M., Shin, S.H., Yoo, W.J. and Lee, B. (2016) Measurement of Gamma-Rays Induced Luminescence Generated in a Sapphire Based Fiber-Optic Radiation Sensor. Journal of Applied Mathematics and Physics, 4, 1503-1506. http://dx.doi.org/10.4236/jamp.2016.48158 
FORS. To evaluate the sensor, we measured the spectrum and intensity of the luminescence generated from the fiber-optic radiation sensor according to the thickness of the PMMA block by irradiation of gamma rays emitted from a Co-60 source. And the result was compared with the value calculated from the formula of Lambert-Beer [9].

\section{Materials and Methods}

In the study, a cylindrical sapphire crystal $\left(\mathrm{Al}_{2} \mathrm{O}_{3}, \mathrm{COMA}\right.$ technology) was used as a sensing material. The diameter and length of the sapphire crystal are $1 \mathrm{~mm}$ and $3 \mathrm{~cm}$, respectively. Also, the refractive index is 1.75 and the density is $3.97 \mathrm{~g} / \mathrm{cm}^{3}$.

A plastic optical fiber (POF, SH6001, Mitsubishi Rayon) was used to transmit the luminescence signal generated from the sapphire crystal to a spectrometer. The core and cladding of transmitting POF are composed of the polymethylmethacrylate (PMMA) and the fluorinated polymer, respectively. The outer diameter of this fiber is $1.5 \mathrm{~mm}$ and the refractive index of the core is 1.49 . The numerical aperture (NA) is 0.5 and the length is $20 \mathrm{~m}$.

To measure the luminescence of the FORS, the spectrometer (QE65000, Ocean Optics) was employed. The range of measurable spectrum is from $200 \mathrm{~nm}$ to $1100 \mathrm{~nm}$ and the SNR is 1000:1. In our experiments, the acquisition time of the RIL signal was fixed at $5000 \mathrm{~ms}$.

Figure 1 shows experimental setup to measure the gamma ray using the sapphire based FORS. The FORS was fabricated with the sapphire crystal, plastic optical fiber and a band pass filter (47B film, Kodak); here, the filter was used to separate the luminescence of the sapphire from the noise signals generated in the plastic optical fibers for transmission. The gamma ray source used in this study is the Co-60 source in the Kyoto University Critical Assembly (KUCA) and its activity is $1047 \mathrm{TBq}$. The distance between theCo-60 source and the FORS was $14 \mathrm{~cm}$. The PMMA blocks having geometrical dimensions of $20 \mathrm{~cm} \times 20 \mathrm{~cm} \times 1 \mathrm{~cm}$ were used to detect the gamma rays as a function of the PMMA thickness. The luminescence generated in the FORS by irradiation of gamma rays is transmitted via 20 m-length plastic optical fiber to the spectrometer.

\section{Results}

Figure 2 shows the spectra of the luminescence generated from the FORS. The luminescence ranged from 400 $\mathrm{nm}$ to $480 \mathrm{~nm}$ with the emission peak at about $420 \mathrm{~nm}$ was observed; this result is caused by the use of the filter. The plastic optical fiber used to transmit the light signals from the sensor probe (sapphire) also produce the RIL by interaction of the gamma rays. In these experiments, the luminescence generated from the sensor probe and the noise signal from the plastic optical fiber are not measured simultaneously but are measured separately at the same position with the Co-60 source. As a result, only the luminescence signals generated from the sapphire were measured using a modified subtraction method [10].

Figure 3 shows the repeatability of the FORS. The luminescence signals were measured 10 times at the same position with the same experimental setup. The measured counts of luminescence were within $\pm 0.065 \%$ line, and the relative standard deviation (\%RSD) of $0.03 \%$ was obtained.

Measured luminescence spectra of the FORS according to the thickness of PMMA block can be found in Figure 4. In this experiment, the count of the luminescence peak decreased with the thickness of PMMA block, because the number of primary or secondary electrons due to gamma interactions are reduced. Figure 5 presents

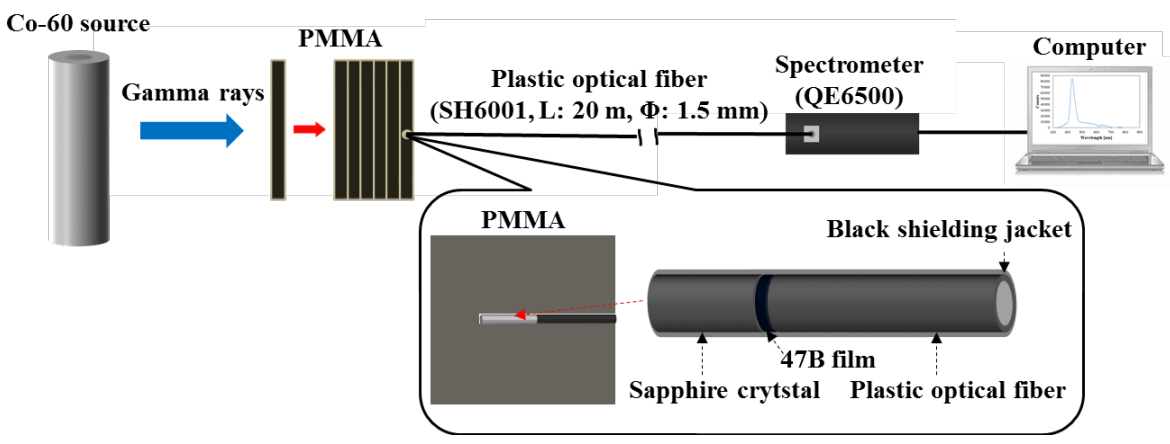

Figure 1. Experimental setup for measuring the luminescence generated in the FORS by irradiation of gamma rays. 


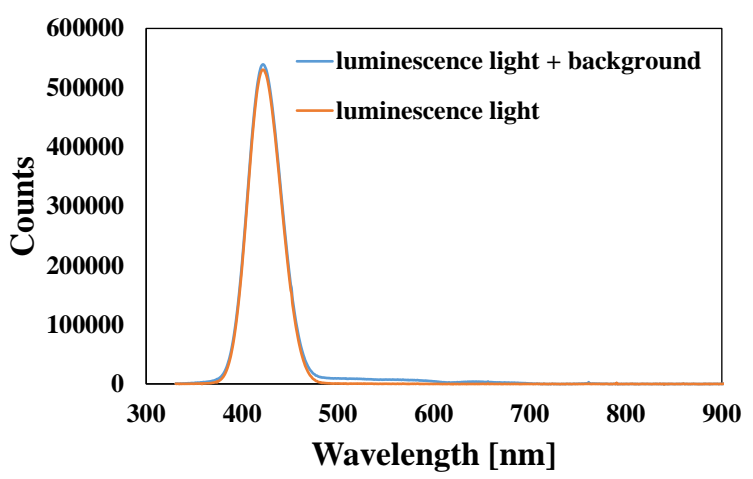

Figure 2. Spectra of the luminescence signals generated in the FORS.

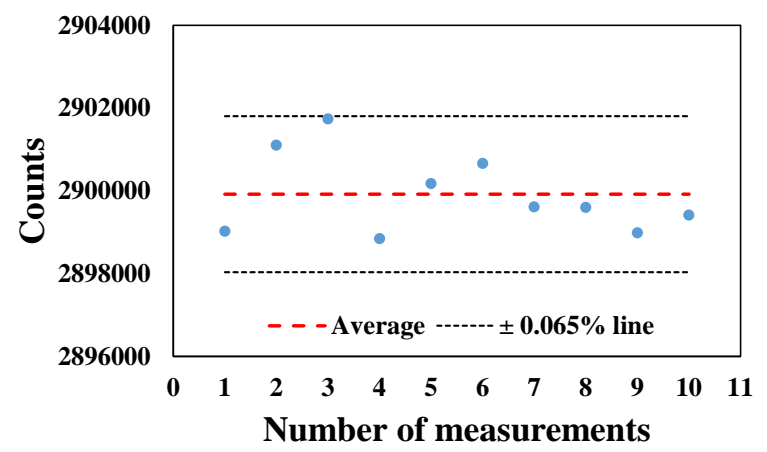

Figure 3. Repeatability of luminescence signals of the FORS.

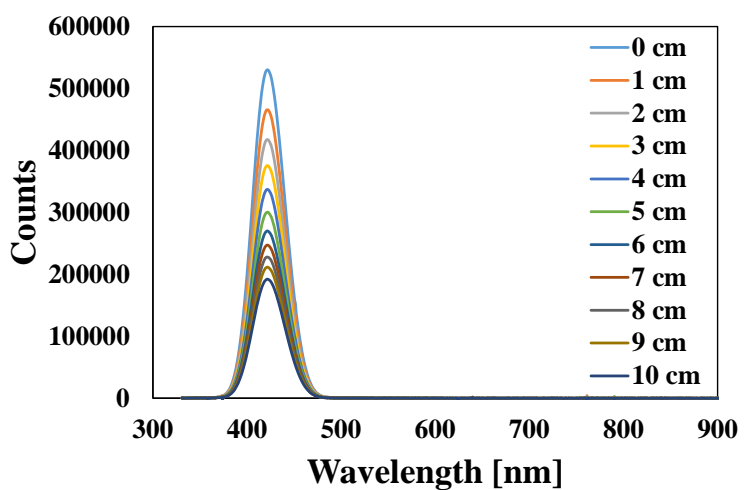

Figure 4. Measured luminescence spectra of the FORS according to the thickness of PMMA block.

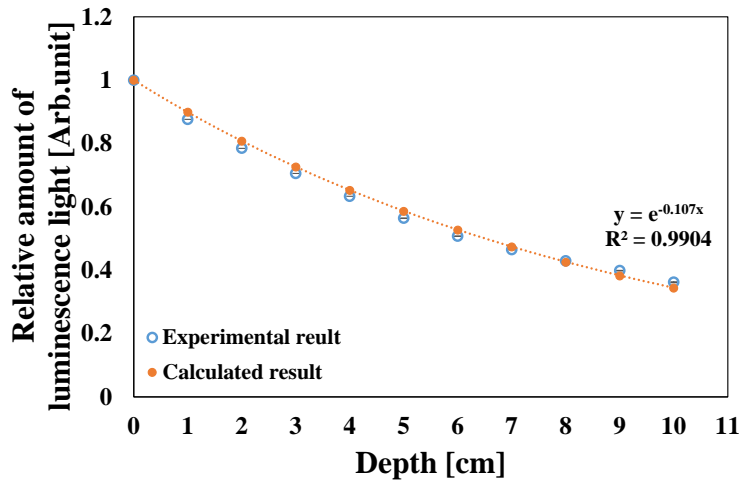

Figure 5. Measured luminescence intensities of the FORS and value calculated using the formula of Lambert-Beer. 
measured luminescence intensities of the FORS according to the thickness of PMMA block and the value calculated from the formula of Lambert-Beer. The measured luminescence intensities of the FORS were in good agreements with the value calculated from the formula of Lambert-Beer.

\section{Conclusion}

In harmful radiation environments, the FORSs have a number of advantages, such as availability in narrow spaces and real-time measurement. In this study, we have fabricated a FORS by using a sapphire, filter, and plastic optical fiber. We measured only the luminescence light generated from the sapphire by using the modified subtraction method. Then, the wavelength range and the peak of the luminescence were measured according to the thickness of PMMA block. Also, the repeatability of the FORS outputs was evaluated. At last, the measured relative intensities of the luminescence according to the thickness of PMMA block were compared with the value calculated using the formula of Lambert-Beer.

\section{Acknowledgements}

This research was supported by National Nuclear R \& D Program through the National Research Foundation of Korea (NRF) funded by the Ministry of Science, ICT and future Planning (2014M2B2A9031841) and this research was supported by Basic Science Research Program through the National Research Foundation of Korea (NRF) funded by the Ministry of Science, ICT and future Planning (2014R1A2A2A04002620 and 2013R1A1A1061647).

\section{References}

[1] Lee, B., Choi, W.Y. and Walker, J.K. (2000) Polymer-Polymer Miscibility Study for Plastic Gradient Index Optical Fiber. Polymer Engineering \& Science, 40, 1996-1999. http://dx.doi.org/10.1002/pen.11331

[2] Arnfield, M.R., Gaballa, H.E., Zwicker, R.D., Islam, Q. and Schmidt-Ullrich, R. (1996) Radiation-Induced Light in Optical Fibers and Plastic Scintillators: Application to Brachytherapy Dosimetry. IEEE Transactions on Nuclear, 43, 2077-2084. http://dx.doi.org/10.1109/23.502302

[3] Han, K.T., Yoo, W.J., Shin, S.H., Jeon, D., Park, J.Y., Park, B.G. and Lee, B. (2012) Development of Fiber-Optic Radiation Sensor Using LYSO Scintillator for Gamma-Ray Spectroscopy. Journal of Sensor Science and Technology, 21, 287-292. http://dx.doi.org/10.5369/JSST.2012.21.4.287

[4] Bartesaghi, G., Conti, V., Prest, M., Mascagna, V., Scazzi, S., Cappelletti, P., Frigerio, M., Gelosa, S., Monti, A., Ostinelli, A., Mozzanica, A., Bevilacqua, R., Giannini, G., Totaro, P. and Vallazza, E. (2007) A Scintillating Fiber Dosimeter for Radiotherapy. Nuclear Instruments and Methods in Physics Research Section A: Accelerators, Spectrometers, Detectors and Associated Equipment, 581, 80-83. http://dx.doi.org/10.1016/j.nima.2007.07.032

[5] Becks, K.-H., Drees, J., Goldmann, K., Gregor, I.M. and Heintz, M. (2000) A Multi Channel Dosimeter Based on Scintillating Fibers for Medical Applications. Nuclear Instruments and Methods in Physics Research Section A: Accelerators, Spectrometers, Detectors and Associated Equipment, 454, 147-151. http://dx.doi.org/10.1016/S0168-9002(00)00817-2

[6] Jursinic, P.A. (2007) Characterization of Optically Stimulated Luminescent Dosimeters, OSLDs, for Clinical Dosimetric Measurements. Medical Physics, 34, 4594-4604. http://dx.doi.org/10.1118/1.2804555

[7] Jang, K.W., Shin, S.H., Kim, S.G., Kim, J.S., Yoo, W.J., Ji, Y.H. and Lee, B. (2014) Measurement of Cerenkov Radiation Induced by the Gamma-Rays of Co-60 Therapy Units Using Wavelength Shifting Fiber. Sensors, 14, 7013-7025. http://dx.doi.org/10.3390/s140407013

[8] Shin, S.H., Jeon, D., Kim, J.S., Jang, J.S., Jang, K.W., Yoo, W.J., Moon, J.H., Park, B.G., Kim, S. and Lee, B. (2014) Measurements of Longitudinal Gamma Ray Distribution Using a Multichannel Fiber-Optic Cerenkov Radiation Sensor. Measurement Science and Technology, 25, 114003-114008. http://dx.doi.org/10.1088/0957-0233/25/11/114003

[9] Soylu, H.M., Yurt Lambrecht, F. and Ersöz, O.A. (2015) Gamma Radiation Shielding Efficiency of a New Lead-Free Composite Material. Journal of Radioanalytical and Nuclear Chemistry, 305, 529-534. http://dx.doi.org/10.1007/s10967-015-4051-3

[10] Beddar, A.S., Mackie, T.R. and Attix, F.H. (1992) Water-Equivalent Plastic Scintillation Detectors for High-Energy Beam Dosimetry: I. Physical Characteristics and Theoretical Considerations. Physics in Medicine and Biology, 37, 1883-1900. http://dx.doi.org/10.1088/0031-9155/37/10/006 


\section{Submit or recommend next manuscript to SCIRP and we will provide best service for you:}

Accepting pre-submission inquiries through Email, Facebook, LinkedIn, Twitter, etc.

A wide selection of journals (inclusive of 9 subjects, more than 200 journals)

Providing 24-hour high-quality service

User-friendly online submission system

Fair and swift peer-review system

Efficient typesetting and proofreading procedure

Display of the result of downloads and visits, as well as the number of cited articles

Maximum dissemination of your research work

Submit your manuscript at: http://papersubmission.scirp.org/ 